\title{
Potential role of a navigator gene NAV3 in colorectal cancer
}

\author{
E Carlsson ${ }^{1,10}$, A Ranki, 1,10, L Sipilä2 ${ }^{2}$ L Karenko',10, WM Abdel-Rahman ${ }^{3,9,10}$, K Ovaska $^{4}$, L Siggberg ${ }^{5}$, Aapola $^{2}$, \\ R Ässämäki', V Häyry', K Niiranen', M Helle ${ }^{7}$, S Knuutila ${ }^{5}$, S Hautaniemi ${ }^{4}$, P Peltomäki ${ }^{3}$ and K Krohn ${ }^{8}$ \\ 'Department of Dermatology and Allergology, University of Helsinki and Helsinki University Central Hospital, PO Box I60, Fl-00029 Helsinki, Finland; \\ ${ }^{2}$ Dermagene Oy, Biokatu 8, Fl-33520 Tampere, Finland; ${ }^{3}$ Department of Medical Genetics, Haartman Institute, University of Helsinki, PO Box 63 , \\ Fl-000 I 4 Helsinki, Finland; ${ }^{4}$ Computational Systems Biology Laboratory, Institute of Biomedicine and Genome-Scale Biology Research Program, University

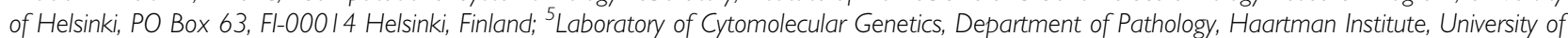 \\ Helsinki, PO Box 63, Fl-000 4 Helsinki, Finland; ${ }^{6}$ Department of Otorhinolanyngology and Helsinki University Central Hospital, University of Helsinki, \\ PO Box 700, Fl-00029 Helsinki, Finland; ${ }^{7}$ Department of Pathology, Mikkeli Central Hospital, Fl-50100 Mikkeli, Finland; ${ }^{8}$ Department of Pathology, \\ Centre for Laboratory Medicine, Pirkanmaa Hospital District, PO Box 2000, Fl-3352I Tampere, Finland
}

BACKGROUND: The recently described navigator proteins have a multifaceted role in cytoskeletal dynamics. We report here on the relevance of one of them, navigator 3 (NAV3), in colorectal cancer (CRC).

METHODS: We analysed changes in chromosome 12 and NAV3 copy number in CRC/adenoma samples of 59 patients and in 6 CRC cell lines, using fluorescence in situ hybridisation, loss of heterozygosity, and array-CGH. NAV3 target genes were identified by siRNA depletion, expression arrays, and immunohistochemistry.

RESULTS: NAV3 deletion and chromosome 12 polysomy were detected in 30 and $70 \%$ of microsatellite stability (MSS) carcinomas, in 23 and $30 \%$ of adenomas and in four of six CRC cell lines. NAV3 amplification was found in $25 \%$ of MSS samples. NAV3 alterations correlated with lymph node metastasis. In normal colon cells, NAV3 silencing induced upregulation of interleukin 23 receptor (IL23R) and gonadotropin releasing hormone receptor. In MSS and microsatellite instability tumours, IL23R immunoreactivity correlated with Dukes' staging and lymph node metastases, whereas nuclear beta-catenin correlated with lymph node metastases only.

CONCLUSION: NAV3 copy number changes are frequent in CRC and in adenomas, and upregulation of IL23R, following NAV3 silencing, strongly correlates with Dukes' staging and lymph node metastases. This suggests that NAV3 has a role in linking tissue inflammation to cancer development in the colon.

British Journal of Cancer (2012) 1 06, 517-524. doi:I0.1038/bjc.20II.553 www.bjcancer.com

Published online 15 December 201।

(C) 2012 Cancer Research UK

Keywords: colorectal carcinoma; adenoma; NAV3; IL23R; beta-catenin

Colorectal cancer (CRC) development from benign precursor lesions, adenomatous polyps, following the accumulation of genetic and epigenetic changes, is one of the best-known examples of multistep carcinogenesis (Vogelstein et al, 1988; Fearon and Vogelstein, 1990; Chung, 2000). Recent evidence also suggests that a permissive tissue microenvironment is critical for the growth potential and spread of tumour cells (Kim et al, 2006; Reuter et al, 2009). Specifically, tumour development is often driven by chronic inflammation. For example, the development of CRC is linked to the presence of inflammatory bowel disease (Xie and Itzkowitz, 2008).

The majority of CRCs display one of two major genomic instability phenotypes, microsatellite instability (MSI) or chromosomal instability with microsatellite stability (MSS; Abdel-Rahman et al, 2001). About $85 \%$ of CRC exhibit MSS, aneuploidy, and loss of heterozygosity ( $\mathrm{LOH})$. Adenomatous polyposis coli (APC) and

\footnotetext{
*Correspondence: Professor A Ranki; E-mail: Annamari.Ranki@hus.fi

${ }^{9}$ Current address: College of Health Sciences, MLT, University of Sharjah, Sharjah, UAE

${ }^{10}$ These authors contributed equally to this work.

Received 2I September 201 I; revised I 4 November 201 I; accepted 21

November 20 I I; published online 15 December 201 I
}

beta-catenin mutations are the most common early molecular aberrations in this phenotype category (Kinzler and Vogelstein, 1996; Polakis, 1997). These mutations lead to aberrant Wnt pathway activation, which is thought to initiate colon adenoma formation. However, second-step activation of KRAS is also needed for adenoma progression to carcinoma (Phelps et al, 2009). The loss of functional $A P C$ also induces aneuploidy in vivo after a transient tetraploidy stage (Caldwell et al, 2007), which may enhance fitness of cells containing broken or rearranged chromosomes.

We have previously shown that chromosome 12q21 aberrations, specifically allelic loss of the neuron navigator 3 (NAV3) gene, are associated with several subtypes of cutaneous T-cell lymphoma (CTCL; Karenko et al, 2005; Hahtola et al, 2008a), CTCL-associated lung cancers (Hahtola et al, 2008b), and ca. $25 \%$ of cutaneous basal and squamous cell cancers (Maliniemi et al, 2011). NAV3 mutations and copy number changes have thereafter been reported in melanoma (Bleeker et al, 2009) and in human glioblastomas, respectively (Nord et al, 2009). In addition, NAV3 was the only differentially expressed gene in adrenal carcinoma relative to adrenocortical adenomas (Soon et al, 2009). In genomic landscaping, NAV3 belongs to the 'hill type' candidate cancer gene group, which is commonly mutated in human breast and colon cancer (Wood et al, 2007). 
We now report that NAV3 copy number changes are found frequently in MSS type CRC, colon adenomas, and established CRC cell lines. NAV3 aberrations correlate with chromosome 12 polysomy and with lymph node involvement. To understand the function of $N A V 3$, we used specific siRNA gene silencing and expression array analysis to identify relevant NAV3 target molecules in normal colon cells. These turned out to be gonadotropin releasing hormone receptor (GnRHR) and interleukin 23 receptor (IL23R). Furthermore, IL23R, GnRHR, and beta-catenin, linked to the GnRH pathway, were upregulated in patient-derived tumour tissue samples and their expression correlated to several unfavourable clinical parameters. Our findings suggest that NAV3 copy number changes promote early carcinogenesis by upregulating IL23R and GnRHR expression, contributing to a microenvironment of inflammation, and providing malignant cells with a growth advantage.

\section{MATERIALS AND METHODS}

\section{Tissue samples}

Surgical biopsy samples were collected from 59 patients (61 CRC and 10 adenoma samples) who underwent surgical resection of CRC tumours at Mikkeli Central Hospital, Mikkeli, Finland. The study was approved by the Ethical Review Board of Mikkeli Central Hospital and by The National Authority for Medicolegal Affairs, Helsinki, Finland. Histology of formalin-fixed, paraffin-embedded tissue samples was assessed by an experienced pathologist ( $\mathrm{MH})$, and tumours, adenomas, or normal mucosa were microdissected after a second analysis by two experienced pathologists (WA-R, $\mathrm{KK})$ to obtain either pure normal epithelium or at least $50 \%$ carcinoma or adenoma tissue. Paraffin-embedded sections were cut at $50-\mu \mathrm{m}$ thickness, nuclei were isolated for fluorescence in situ hybridisation (FISH) analysis, and DNA was purified for LOH analysis following standard protocols (Hyytinen et al, 1994; Isola et al, 1994). All adenomas were MSS, whereas 14 of the 56 carcinomas had high-degree MSI (MSI analysis in Supplementary Online Materials, Method 1). The following parameters were recorded from each patient: tumour grade and stage by Dukes and TNM classification as defined by the American Cancer Society (Oklahoma City, OK, USA), presence of lymph node metastasis, follow-up time, and clinical outcome.

\section{Cells and cell lines}

CRL-1541 (CCD-112CoN) and CRL-1539 (CCD-33Co; ATCC Manassas, VA, USA) normal colon cells, and CRC cell lines CCL228 (SW480), CCL-230 (SW403), CCL-248 (T84), CRL2577 (RKO), LIM1215, and HCA7 (ATCC), were grown as instructed by ATCC. All assays on CRL-1541 and CRL-1539 cell were performed on cells provided by ATCC that were grown for no more than six passages. Colon carcinoma cell lines CCL-228, CCL-230, CCL-248, and CRL2577 were also provided by ATCC and grown for a maximum of 20 passages before use. Metaphase preparates of LIM1215 and HCA7 cells were provided by professor Päivi Peltomäki, and cells have previously been described in detail (Abdel-Rahman et al, 2001; Joensuu et al, 2008). RKO, LIM1215, and HCA7 are mismatch repair deficient and have MSI.

\section{Fluorescence in situ hybridisation}

NAV3-specific FISH was performed on nuclei isolated from tissue samples (Hyytinen et al, 1994; Isola et al, 1994) and on metaphase chromosomes of colon carcinoma cell lines. Bacterial artificial chromosome clones containing NAV3 DNA (RP11-36P3 and RP11136F16; Research Genetics Inc., Huntsville, AL, USA) and the chromosome 12 centromere probe (pA12H8; ATCC) were labelled with Alexa 594-5-dUTP and Alexa 488-5-dUTP (Invitrogen,
Carlsbad, CA, USA), respectively, for tissue samples, or with digoxigenin and biotin, respectively, for cell lines. Detailed methods for probe labelling, slide preparation, and arm-specific MFISH are provided in Supplementary Online Materials, Method 2. The FISH results of the tissue samples were analysed by two blinded, independent researchers. Results are reported as the percentage of abnormal nuclei in 200 total nuclei as previously described (Ranki et al, 2011). For each cell line, 9-47 metaphases were analysed for NAV3 and centromere 12, whereas 5-11 metaphases were analysed for arm MFISH.

\section{NAV3 LOH analysis using microsatellite markers and single-nucleotide primer ex tension}

NAV3 LOH assays were performed as previously described (Hahtola et al, 2008b). In addition, the A/G polymorphism (rs1852464) within exon 19 of the NAV3 gene, which exhibits up to 0.493 heterozygosity in Caucasians/Europeans, was used in the single-nucleotide primer extension reaction. Detailed methods are provided in Supplementary Online Materials, Method 3. Tumour samples were defined as showing $\mathrm{LOH}$, if one allele had $40 \%$ more or less rs1852464 signal than matched normal tissue. In the event of constitutional homozygosity, $\mathrm{LOH}$ was assessed using flanking microsatellite markers (Cleton-Jansen et al, 2001).

\section{Array CGH}

DNA was extracted from $50-\mu \mathrm{m}$ paraffin-embedded tissue sections by standard protocols. Reference DNA was extracted from blood pooled at the Finnish Red Cross (Helsinki, Finland) from four healthy males and females after informed consent. DNA was then digested, labelled, and hybridised to a $244-\mathrm{K}$ oligonucleotide array according to the manufacturer's protocol (Agilent Technologies, Santa Clara, CA, USA). Samples were scanned with a DNA microarray scanner and analysed using Feature Extraction v. 9.5.3.1 and CGH Analytics software v. 3.5.14 (Agilent Technologies). Analysis was performed using the $Z$-score and a $1-\mathrm{Mb}$ moving average window. Log2-values under \pm 0.4 were not considered aberrant. Three colon carcinoma cell lines and two colon carcinoma tumour samples were analysed.

\section{NAV3 gene silencing in vitro}

The NAV3 gene was silenced with pooled siRNA oligonucleotides (On-Target SMART pool, Dharmacon, Chicago, IL, USA) as instructed by the producer. The CRL-1541 and CRL-1539 cell lines were transfected with $200 \mathrm{pmol} N A V 3$ pooled siRNA or scrambled control siRNA (Dharmacon), using Dharmafect1 transfection reagent (Dharmacon; for details see Supplementary Online Materials, Method 4). Efficient knockdown was confirmed by qPCR and microarrays (as shown in Supplementary Figure 1). Efficient NAV3-silencing and upregulation of IL23R and GnRHR were confirmed by LightCycler qPCR (Roche, Basel, Switzerland) using TBP (tata box binding protein) as reference gene for normalisation (primers used are given in Supplementary Table 1). As according to the manufacturer, the optimal timepoint for RNA knockdown assessment is $24-48 \mathrm{~h}$, the following post-transfection RNA samples were analysed on Agilent $4 \times 44 \mathrm{~K}$ microarrays: CRL-1541 (6 and 48h) and CRL-1539 (6 and 24h).

\section{Gene expression microarrays and microarray analysis}

To identify genes regulated by $N A V 3$, changes in gene expression profiles induced with NAV3-targeted RNAi were analysed with Agilent $4 \times 44 \mathrm{~K}$ dual-color microarrays (Biochip Center, Biomedicum Helsinki, http://www.helsinki.fi/biochipcenter/). RNA was purified with RNeasy Micro or Mini Kit (Qiagen, Hilden, Germany) and stored at $-70^{\circ} \mathrm{C}$. Total RNA obtained from the 
NAV3-silenced cells was hybridised with the corresponding time point samples from the same cells transfected with scrambled oligonucleotides. Before hybridisation, RNA sample quality was assessed with a 2100 Bioanalyzer (Agilent Technologies). The microarray data from the four normal colon cell lines were analysed using the Anduril bioinformatics framework (Ovaska et al, 2010). Probe intensities were background corrected and normalised with LOWESS, using Agilent Feature Extractor 9.1.3.1. Genes with fold change $>2$ or $<0.5$ in all samples were considered as differentially expressed. Stringent quality control, which removes probes not flagged as above background by Agilent Feature Extractor, resulted in only one differentially expressed gene in addition to NAV3. Accordingly, the quality filtering criteria were loosened to include genes with low signal intensity. Probes whose sequence could not be uniquely mapped to Ensembl v.56 transcripts were discarded (Gertz et al, 2009).

\section{Immunohistochemistry on tissue microarrays}

IL-23R and beta-catenin expression was studied by immunohistochemistry of tissue microarrays prepared from paraffinembedded colon biopsies of the above patients. From each patient, paired samples from the histologically normal colon and two samples from the colon tumour were included. Also, 10 paired samples of an adenomatous lesion and another sample from the normal colon were included. Altogether, 57 patients, 43 MSS tumour samples, 14 MSI tumour samples, 14 adenoma samples, and 57 corresponding normal colon samples were included. Detail methods are available in Supplementary Online Materials, Method 5. For statistical analysis, samples were scored as follows: for IL-23R immunoreactivity: no staining (score 0 ), weak positive staining (score 1), clear positive staining (score 2 ), strong positive staining (score 3); for beta-catenin: no staining (score 0 ), cell membrane staining (score 1), cytoplasmic staining (score 2), only nuclear staining in the majority of tumour cells (score 3 ).

\section{Statistical analysis of tissue samples}

Correlations between categorical variables studied were analysed using the $\chi^{2}$-test, or when not valid, the Fisher's exact test. Also, the following parameters were included in the statistical analysis: tumour grade and stage by Dukes and TNM classification, presence of lymph node metastasis, follow-up time, and clinical outcome. Survival analyses were performed using death caused by colon cancer as the primary endpoint. Follow-up times were obtained from Statistics Finland (Helsinki, Finland). SPSS version 15.0 software (SPSS Inc., Chicago, IL, USA) was used.

\section{RESULTS}

\section{NAV3 copy number changes are found in CRC and colorectal adenomas}

Cells with NAV3 copy number changes were detected in $40 \%$ of MSS-type colorectal carcinoma samples as follows: a mixed cell population of those with $N A V 3$ deletion and those with $N A V 3$ amplification was detected in $15 \%$ of samples, NAV3 deletion alone in $15 \%$, and low levels of NAV3 amplification (three to five copies) alone in $10 \%$. Cells with NAV3 deletion were also detected in $12.5 \%$ of MSI-type samples and $23 \%$ of adenoma samples. In addition, cells with chromosome 12 polysomy, most often three or five copies, were detected in $70 \%$ of MSS-type colorectal carcinoma samples, $50 \%$ of MSI-type samples, and $31 \%$ of adenoma samples (Figure 1). NAV3 copy number changes were confirmed by LOH assay, and $\mathrm{LOH}$ was detected in $21 \%$ of MSS carcinomas and in $18 \%$ of adenoma samples overall (marker-specific frequencies for $\mathrm{LOH}$ are given in Table 1).
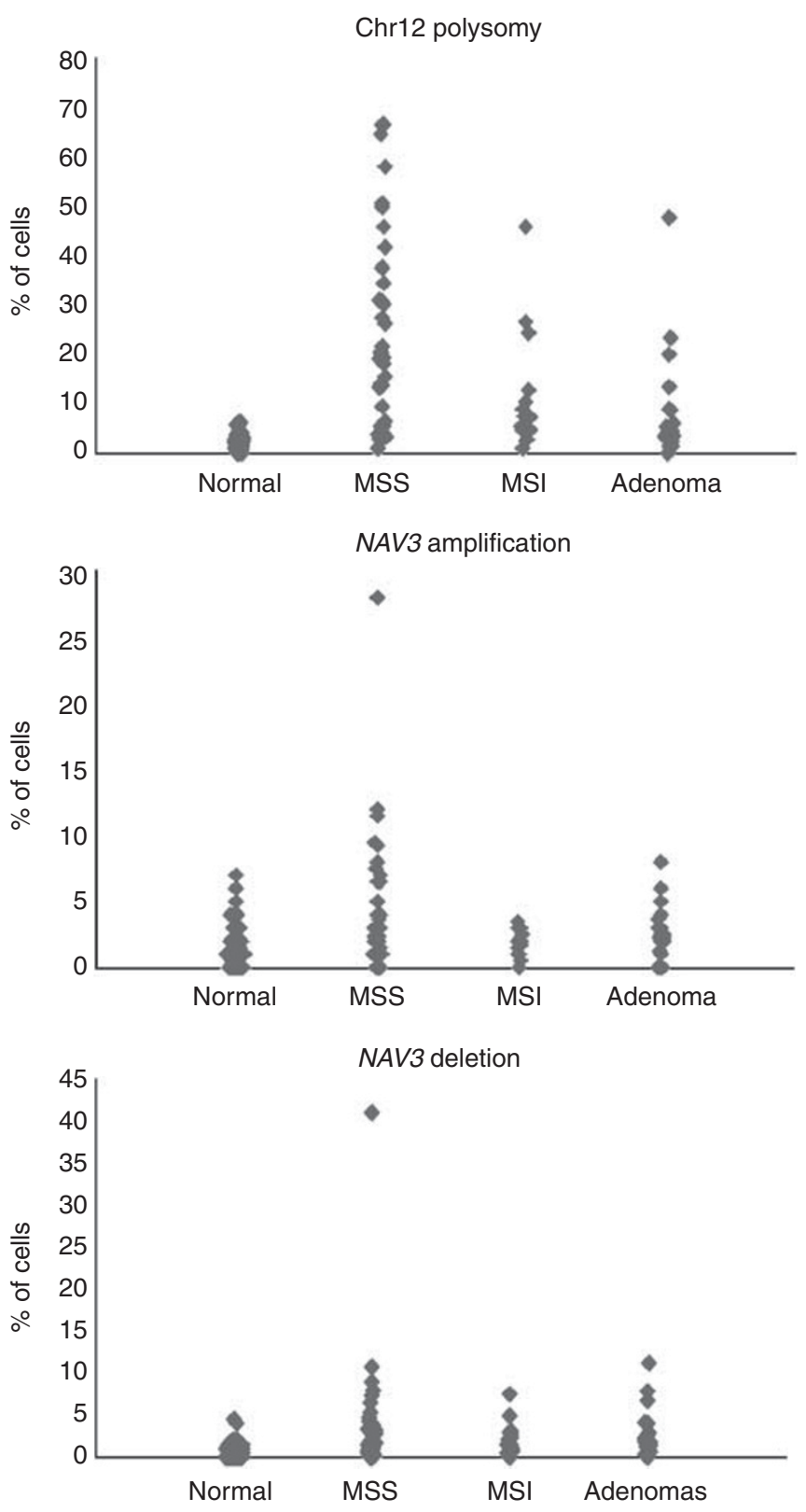

Figure I (A) Chromosome 12 polysomy, (B) NAV3 amplification, and (C) NAV3 deletion in normal colon, MSS, and MSI colon carcinoma and in colon adenoma samples. Each bullet represents one sample and 200 cells were counted per sample.

Table I NAV3 LOH results for each marker

\begin{tabular}{lllcl}
\hline & DI2SI684 & DI2S326 & SNuPE@rs I852464 & DI2SI708 \\
\hline CRC, MSS & $8 / 37(22 \%)$ & $10 / 33(30 \%)$ & $4 / 23(17 \%)^{\mathrm{a}}$ & $5 / 29(17 \%)$ \\
CRC, MSI & $0 / 3$ & $0 / 2$ & $0 / 7^{\mathrm{a}}$ & $0 / 4$ \\
Adenoma & $1 / 21(5 \%)$ & $2 / 19(11 \%)$ & $0 / 8^{\mathrm{a}}$ & $2 / 16(13 \%)$
\end{tabular}

Abbreviations: $\quad \mathrm{CRC}=$ colorectal cancer; $\mathrm{LOH}=$ loss of heterozygosity; $\mathrm{MSI}=$ microsatellite instability; $\quad \mathrm{NAV} 3=$ navigator $3 ; \quad \mathrm{SNuPE}=$ single-nucleotide primer extension. ${ }^{\mathrm{a}} \mathrm{LOH}$ frequencies were based on informative cases. SNuPE test was uninformative due to constitutional homozygosity in five carcinomas and in all adenomas that showed $\mathrm{LOH}$ by chromosome 12 microsatellites examined.

Comparison of NAV3 copy numbers between adenoma and carcinoma samples from the same intestinal resection samples of a given patient revealed that $N A V 3$ deletion also was frequently 


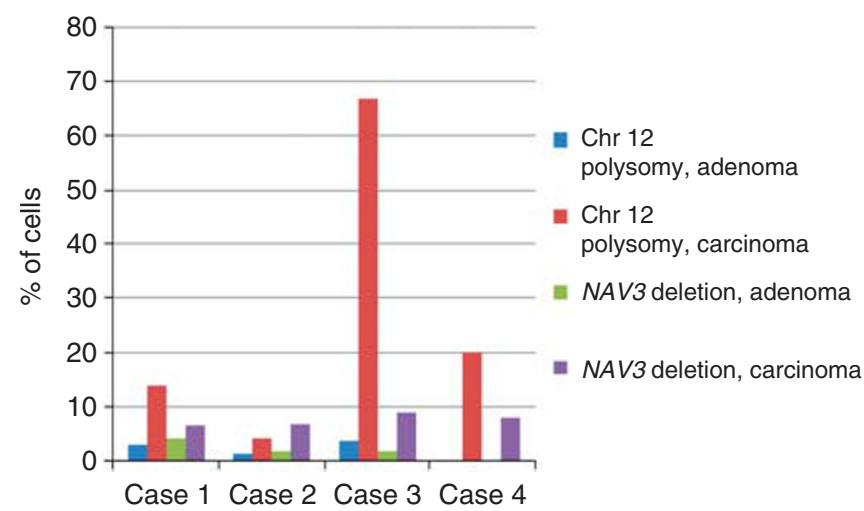

Figure 2 Amount of chromosome 12 polysomic and NAV3-deleted cells in adenoma and carcinoma samples from the same patients.

detectable at the adenoma stage, however at lower frequency than in the corresponding carcinoma sample (Figure 2).

\section{NAV3 aberrations associate with chromosome 12 polysomy and lymph node metastasis}

NAV3 copy number changes correlated significantly with chromosome 12 polysomy and with lymph node metastasis (Table 2). No statistically significant correlations were found between NAV3 status, Dukes' stage, tumour grade, or patient history of other malignancies. For survival analysis, this patient cohort was not appropriate, as the follow-up time was short and the homogeneity of treatment could not be guaranteed.

\section{CRC cell lines show NAV3 copy number changes or translocations}

Six established CRC cell lines and two normal colon cell lines were analysed with NAV3-specific FISH (Supplementary Table 2). The normal colon cells CRL-1541 and 92\% of CRL-1539 cells showed no aberrant NAV3 or chromosome 12 centromere signals, and the remaining $8 \%$ of CRL-1539 cells were tetrasomic nuclei. CCL-230 (>90\%), CRL-2577 (>40\%), and CCL-248 (>90\%) cells displayed NAV3 deletion. Cells of the near-diploid line CCL-228 typically showed one normal chromosome 12, two abnormal chromosomes missing NAV3, and one abnormal chromosome with NAV3-signal, but no chromosome 12 centromere signal. A translocation of $N A V 3$ to another chromosome, interpreted as $\mathrm{t}(2 ; 12)$ by arm MFISH, was observed in all metaphases, except one (Figure 3 and Supplementary Table 2).

\section{Array-CGH analysis of tumour tissue and CRC cell lines}

Array-CGH studies were performed on two patient samples and on three established CRC cell lines. Array-CGH data demonstrated a deletion in 12q21, spanning the NAV3 locus in one patient sample, thus confirming the FISH results (patient sample had $41 \%$ NAV3 deleted cells by FISH; Supplementary Figure 2). However, the other patient sample showed normal results by this analysis, probably due to an insufficient proportional number of $N A V 3$ aberrant cells in the sample ( $28 \%$ of cells showing amplified NAV3 signals by FISH). Array-CGH analysis of colon carcinoma cell lines showing NAV3 loss by FISH revealed major alterations in chromosome 12, as well as in other chromosomes, as was expected for cultured cancer cells. In the CLL-230 line, a wide deletion spanning the NAV3 locus was detected in 12q. This deletion was not detected in the other two cell lines (CLL-248 and CLL-228), which instead had amplifications of other parts of the chromosome.
Table 2 Correlations between NAV3 copy number, chromosome 12 polysomy, tumour grade, Dukes' stage, and metastasis

\begin{tabular}{|c|c|c|c|c|}
\hline & $\begin{array}{l}\text { Chromosome } \\
12 \text { polysomy }\end{array}$ & $\begin{array}{l}\text { Tumour } \\
\text { grade }\end{array}$ & $\begin{array}{l}\text { Dukes } \\
\text { grade }\end{array}$ & $\begin{array}{l}\text { Lymph node } \\
\text { metastases }\end{array}$ \\
\hline $\begin{array}{l}\text { NAV3 copy number } \\
\text { change }\end{array}$ & $\begin{array}{c}P=0.005 \\
n=54\end{array}$ & $\begin{array}{c}n s \\
n=51\end{array}$ & $\begin{array}{c}n s \\
n=51\end{array}$ & $\begin{array}{c}P=0.045 \\
n=51\end{array}$ \\
\hline $\begin{array}{l}\text { Chromosome } 12 \\
\text { polysomy }\end{array}$ & & $\begin{array}{l}P=n s \\
n=51\end{array}$ & $\begin{array}{c}\text { ns } \\
P=51\end{array}$ & $\begin{array}{c}P=0.023 \\
n=51\end{array}$ \\
\hline $\begin{array}{l}\text { Nuclear beta- } \\
\text { catenin expression }\end{array}$ & $\begin{array}{c}n s \\
n=47\end{array}$ & $\begin{array}{c}n s \\
n=49\end{array}$ & $\begin{array}{c}n s \\
n=49\end{array}$ & $\begin{array}{c}P=0.048 \\
n=49\end{array}$ \\
\hline $\begin{array}{l}\text { Upregulated IL-23R } \\
\text { immunoreactivity }\end{array}$ & $\begin{array}{c}n s \\
n=46\end{array}$ & $\begin{array}{c}n s \\
n=47\end{array}$ & $\begin{array}{c}P<0.001 \\
n=47\end{array}$ & $\begin{array}{c}P<0.00 I^{a} \\
n=47\end{array}$ \\
\hline
\end{tabular}

Abbreviations: $\quad \mathrm{L} 23 \mathrm{R}=$ interleukin 23 receptor; $\mathrm{NAV} 3=$ navigator 3 ; $\mathrm{ns}=$ not statistically significant. Fisher's exact test was used if not otherwise indicated. ${ }^{a} \chi^{2}$-test.

NAV3 gene silencing results in the upregulation of GnRHR and IL23R in normal colon cell lines and corresponding association is seen in CRC cell lines with NAV3 deletions

To identify in vivo relevant target genes of NAV3, we studied the gene expression profiles of NAV3-silenced normal colon cells (with normal $N A V 3$ gene copy numbers). On the basis of the microarray data, we selected two membrane receptors, GnRHR (fold change $>14$ in all cell lines) and $I L 23 R$ (fold change $>4$ in all cell lines), from the list of 55 putative differentially expressed genes (Supplementary Table 3) for further analysis. Both GnRHR and $I L 23 R$ receptors are involved in carcinogenesis by activating GnRHR and Jak-STAT pathways, respectively. These genes were also the only ones directly connected to downstream signalling pathways, and thus, of special interest. Upregulations were confirmed with qPCR when NAV3-silenced cells (CRL-1541, $48 \mathrm{~h}$ post-transfection) were compared with control cells showing twofold increase in GnRHR and four-fold increase in IL-23R mRNA levels. In addition, when studying $N A V 3$ expression with qPCR in a CRC cell line with NAV3 deletions, decreased NAV3 mRNA levels were observed compared with the normal colon cells (Supplementary Table 4). In line with the siRNA gene silencing results, the IL23R mRNA level was increased in the CRC cell line CCL-248 with 90\% NAV3 deletions compared with the normal colon epithelial cells (Supplementary Table 3).

\section{Expression of IL-23R in MSS tumours correlated with Dukes' staging and lymph node metastasis}

Immunohistochemical detection of beta-catenin (linked to the GnRH pathway) (Salisbury et al, 2008) and IL-23R expression was performed on a tissue microarray of 43 MSS (including 8 matched adenoma samples) and 14 MSI (matched tumour and normal colon epithelium) patient samples. In all but three normal colon samples, beta-catenin staining was membranous and IL-23R expression was undetectable or weak (grade 1). Samples with allelic NAV3 deletions frequently showed upregulated IL-23R expression, ranging from weak positive staining to strong positive staining (Figure 4). Beta-catenin is known to localise to the cell membrane in normal epithelial tissue, but relocalise to the nucleus and cytoplasm in carcinoma tissue (MacDonald et al, 2009). Duplicate analysis of MSS tumour samples revealed only nuclear betacatenin in 10 of 43 samples and upregulation of IL-23Rimmunoreactivity in 27 of 43 samples. The nuclear beta-catenin expression correlated with lymph node metastasis (Table 2). Upregulated IL-23R immunoreactivity correlated with Dukes' staging and lymph node metastases (Table 2). 


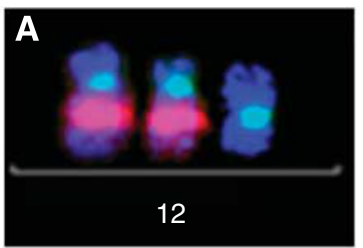

D

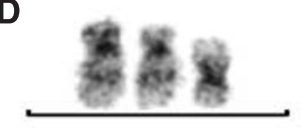

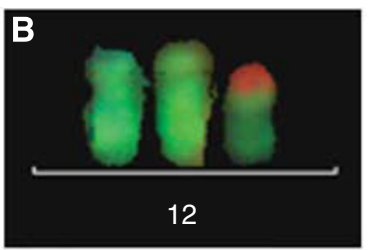

E

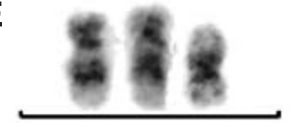

12

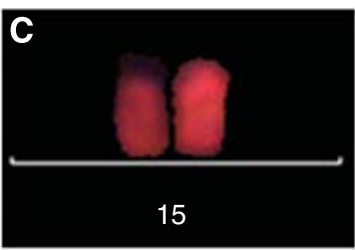

$\mathbf{F}$

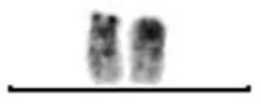

15
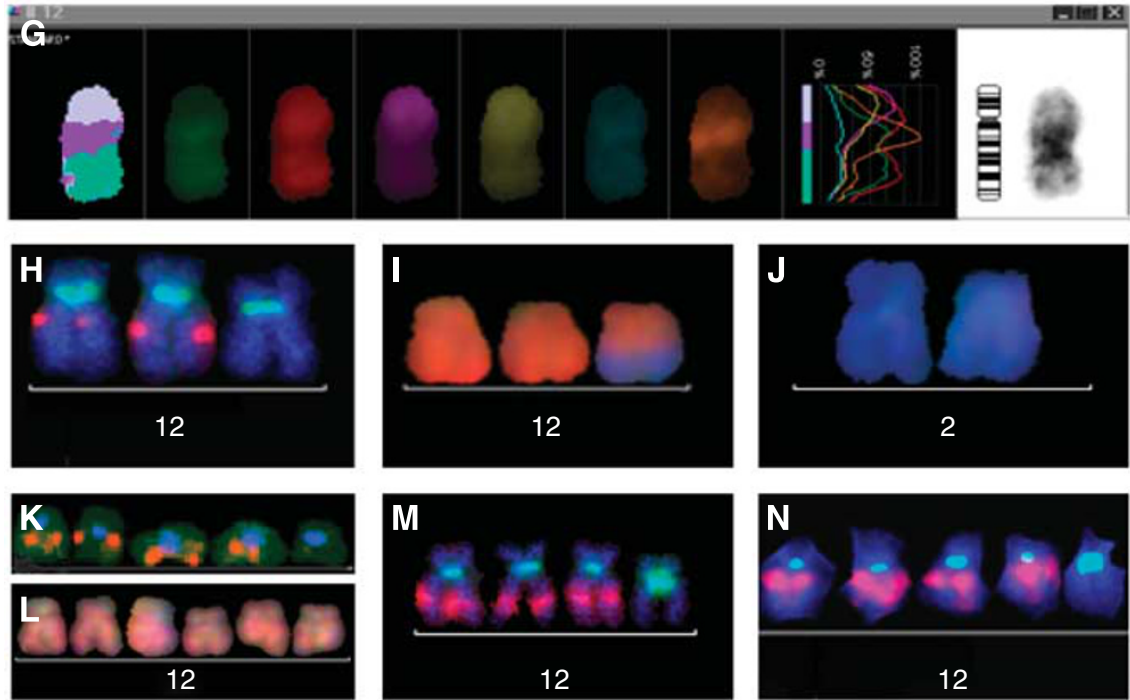

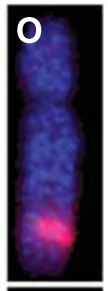

2

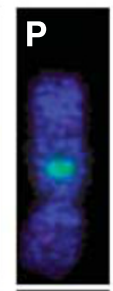

10

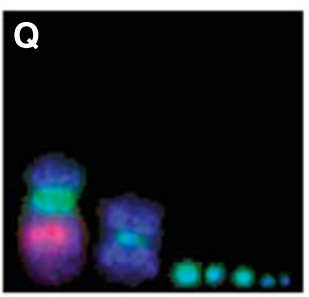

12

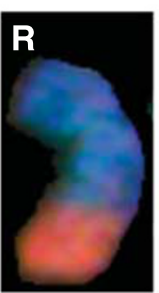

2
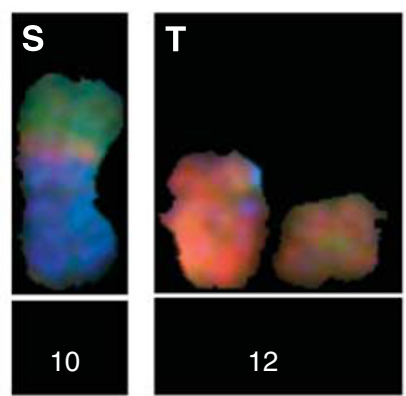

Figure 3 Moleculocytogenetic specification of chromosome 12 and NAV3 aberrations in colon cancer cell lines. The aberrant cells of lines CCL-230 (A- $\mathbf{G})$ and CRL-2577 (H-J) most commonly showed three copies of chromosome 12 ( $\mathbf{A}$. H: centromere 12 green), with loss of NAV3 by specific bacterial artificial chromosome (BAC)-probes in one of them (A: RPI I -36P3 red, H: RP I I- I 36F I 6 red). In the cell line CCL-230, a translocation from chromosome I5 (B, C: red; $\mathbf{G}$ : wine-red in arm-MFISH) to chromosome 12 (B and $\mathbf{G}$ : green) was specified to 12p (G: orange), and 12q showed a deletion (D-F: shortened q-arm and change of the inverted DAPI banding pattern). In the cell line CRL-2577, an unbalanced translocation between chromosomes 12 (I: red, MFISH) and 2 (I, J: blue, MFISH) abolished the NAV3 gene. The line CLL-248 mostly showed five copies of chromosome I2, one of them missing NAV3 (K: centromere 12 blue, BAC RPI I-36P3, orange), but no translocations in arm-MFISH (L). The deletion extended to the regions defined by YAC probes $825 F 9(\mathbf{M})$ and $885 G 4(\mathbf{N})$. In the line CLL-228, (- $-\mathbf{T})$ the NAV3- specific signal (RPI I-36P3, red) was seen in one abnormal chromosome (O) and in the normal chromosome 12 (Sub-figure $\mathbf{Q}$ ), but not in two other chromosomes with centromere 12 (Sub-figures $\mathbf{P}, \mathbf{Q}$ : centromere 12 green), nor in the minute chromosomes with centromere 12 material (Sub-figure $\mathbf{Q}$ : green). The corresponding aberrant chromosomes by arm-MFISH (R-T) are $t(2 ; 12$ ) (R: blue; orange), der (I0)t(I0; I ; 3) (S: blue; orange; green) and $\mathrm{i}(12)(\mathrm{p})$ ( $\mathbf{T}$ : orange, the aberrant chromosome is on the right, a normal chromosome I2 is on the left). YAC-and BAC probes as published previously (I2).

For 11 MSS-type CRC patients, it was possible to compare the IL23R, beta-catenin, and NAV3 FISH results in matched adenoma and tumour samples. NAV3 copy number changes and elevated IL-23R expression (moderate or strong immunostaining), and/or nuclear beta-catenin were present in three of the adenoma samples. Elevated IL-23R expression alone was present in two additional adenomas (data not shown). In the corresponding tumour samples, the finding was similar, except that two samples had no NAV3 aberrations despite the presence of upregulated IL-23R expression. In both cases, the corresponding adenoma lesion had chromosome 12 polysomy.
Because of the small number of adenoma samples in these surgical resections, it was not possible to assess correlation between the NAV3 copy number changes, IL-23R and beta-catenin expression, biological behaviour, and prognostic features of the disease.

\section{DISCUSSION}

The current paper describes copy number changes in chromosome 12 centromere, and in the NAV3 gene, located in $12 \mathrm{q} 21$, in a 

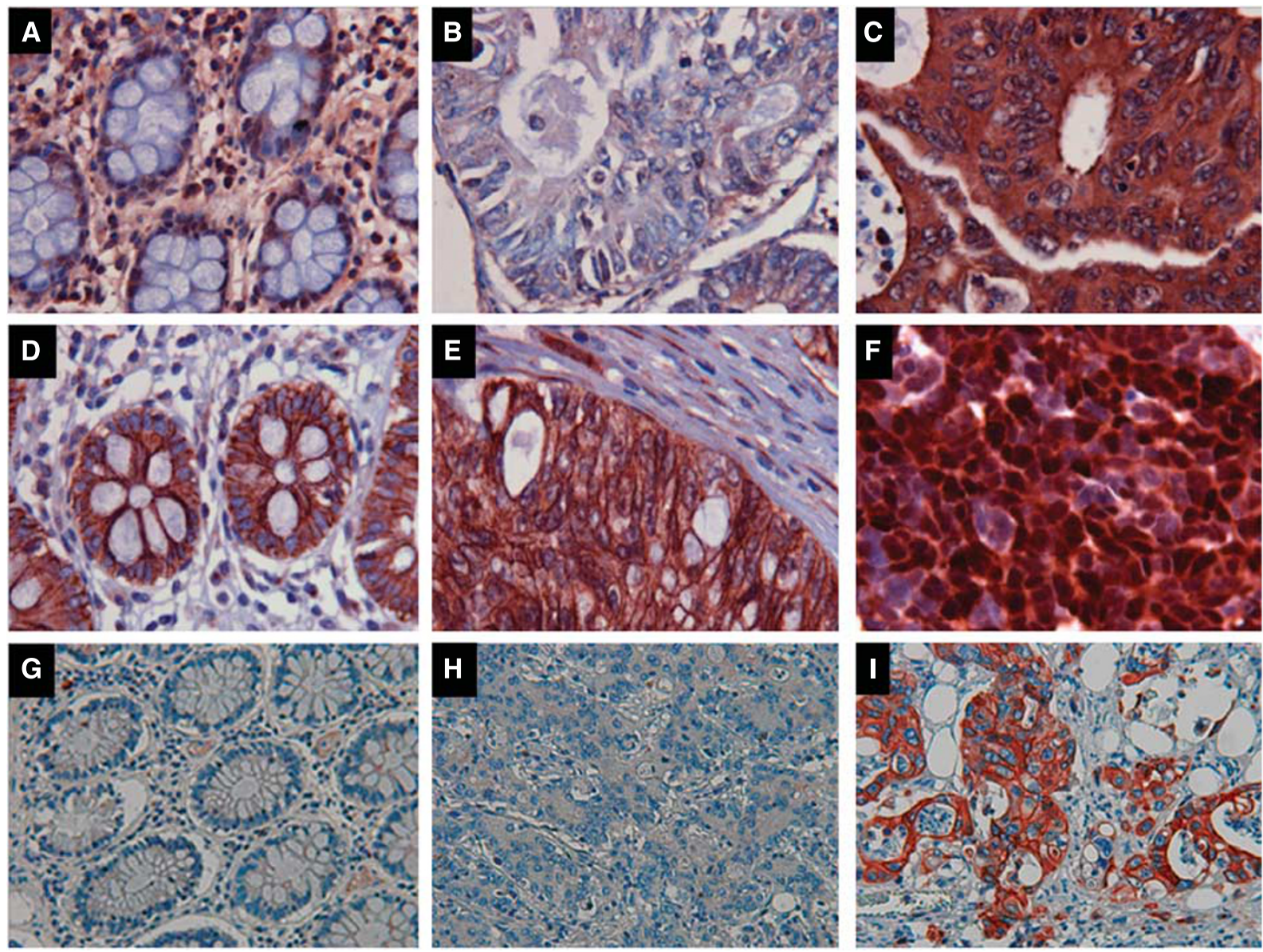

Figure 4 Expression and cellular localisation of IL23R and beta-catenin in human colon and CRC. Representative photomicrographs of immunostaining for IL23R (A) and beta-catenin (D) in normal colon tissue. Upregulated IL23R immunoreactivity was observed in CRC samples with NAV3 deletion (C) strongest grade 3 immunostaining), whereas cancers without NAV aberration showed no IL23R staining (B). Both samples (B and C) had 20\% tumour cells with chromosome 12 polysomy. A CRC sample with no NAV3 deletion showed normal membranous pattern of beta-catenin staining (E) whereas a CRC sample with NAV3 deletion in $9 \%$ of the cells showed mainly strong nuclear localisation of beta-catenin (F). NAV3 immunostaining of normal colon (G), of CRC with NAV3 deletion $(\mathbf{H})$ and an area of a CRC tumour with amplified NAV3 (I).

substantial number of cases of colorectal carcinomas or colon adenomas. Furthermore, the functional consequences of NAV3 deletion were characterised with siRNA silencing experiments. The NAV3 copy number changes correlated with chromosome 12 polysomy, as well as with the occurrence of lymph node metastases in the patients.

An obvious question to be addressed is whether the observed NAV3 aberrations would just reflect copy number changes in larger areas of chromosome 12. The LOH method used in this study, would not by itself have excluded such an interpretation as changes close to the location of the NAV3 gene (for example, the cancer implicated gene E2F7 (Endo-Munoz et al, 2009)) would also have shown loss of heterogeneity in this assay. However, the E2F7 gene sequence is outside the FISH probe used to enumerate NAV3 copy numbers in the studied samples. Also, the FISH probe does not cover the 12q13.13 locus recently identified as an additional CRC susceptibility locus (Houlston et al, 2010).

Another question of importance is whether the observed NAV3 aberrations would be causative factors ('driver alterations') in cancer formation or spread, or whether they would represent secondary changes. Generally, features that would support a 'driver' action of a given gene or alteration include a high frequency of alterations, several alternative types of changes that can inactivate/activate a gene, involvement of many different types of tumours, being part of a relevant biological pathway, and experimental evidence of important functional consequences
(Boland et al, 1998; Leary et al, 2008; Kalari and Pfeifer, 2010). Most of these general characteristics of a causative factor apply to NAV3, as demonstrated by others and us. Frequent NAV3 copy number changes were identified in CTCL (Karenko et al, 2005) and in two other epithelial cancers: basocellular and squamocellular carcinomas of the skin (Maliniemi et al, 2011). In CTCL, deletion of NAV3 correlated with poor prognosis or with poor response to therapy (Ranki et al, 2011). Earlier studies by Wood et al (2007) show that NAV3 is a 'hill-type' cancer gene, and that in CRC, there are several different point mutations in this gene. In contrast to APC mutations that are all truncating and would lead to inactivation of the gene, the NAV3 point mutations are of missense type and could thus theoretically lead both to increased or decreased activity. NAV3 is a helicase and it was recently shown that a similar gene, the helicase-like transcription factor (HLTF), can have a dual-type of activity, behaving both as an oncogene and as a tumour suppressor (Debauve et al, 2008). Finally, NAV3 silencing experiments described in the present investigation provide evidence that a proper function of NAV3 is critical for central biological processes relevant for tumourigenesis.

To further characterise the biological effect of NAV3 deletion, NAV3 expression was silenced with siRNA in normal colon cells, with normal NAV3 copy numbers. In these studies, the upregulation of two signalling pathways, the Jak-STAT and GnRH pathways (regulated by IL-23R and GnRHR, respectively) were seen. 
Strong IL23R expression and the translocation of beta-catenin, regulated by the $\mathrm{GnRH} / \mathrm{GnRHR}$ pathway, were seen in some of the patient samples and correlated with signs of poor prognosis, namely Dukes' staging and the presence of lymph node metastasis. Also, IL23R mRNA level was upregulated in a colon carcinoma cell line showing up to $90 \%$ cells with NAV3 deletion.

The GnRHR/GnRH signalling pathway in extrapituitary tissues, and in a variety of tumours, is thought to be related with nonclassical GnRHR signalling pathways, including the regulation of several proteins associated with cell proliferation and cell motility (reviewed in Aguilar-Rojas and Huerta-Reyes (2009)). GnRHR is known to transmit signals via beta-catenin (Salisbury et al, 2008; Gardner and Pawson, 2009), the key signalling molecule of the canonical Wnt pathway (Gordon and Nusse, 2006), whereas growth factors and inflammatory factors have been suggested to activate the Wnt pathway in CRC to stimulate the mobility of tumour cells (DeNardo et al, 2008). Our observation of GnRHR upregulation as a consequence of NAV3 silencing in normal human colon cells and, correspondingly, the correlation of nuclear beta-catenin expression with lymph node metastases in the clinical CRC samples substantiates the role of NAV3 as one of such activating factors.

The upregulation of the IL23R in CRC is of interest in view of previous reports on significantly elevated mucosal levels of $I L 23 R$ mRNA in Crohn's disease (Kugathasan et al, 2007; Holtta et al, 2008 ) and more recent reports linking an IL23R polymorphism to the development of inflammatory bowel diseases, typically with an increased risk of CRC (Lakatos et al, 2008; Einarsdottir et al, 2009; Silverberg et al, 2009; Yang et al, 2009). Thus, future prospective studies will need to verify whether a smouldering inflammation with IL-23 secreted by activated inflammatory cells (Brand, 2009) in the intestinal microenvironment would contribute to the development of sporadic CRC as well.

\section{REFERENCES}

Abdel-Rahman WM, Katsura K, Rens W, Gorman PA, Sheer D, Bicknell D, Bodmer WF, Arends MJ, Wyllie AH, Edwards PA (2001) Spectral karyotyping suggests additional subsets of colorectal cancers characterized by pattern of chromosome rearrangement. Proc Natl Acad Sci USA 98: $2538-2543$

Aguilar-Rojas A, Huerta-Reyes M (2009) Human gonadotropin-releasing hormone receptor-activated cellular functions and signaling pathways in extra-pituitary tissues and cancer cells (Review). Oncol Rep 22: $981-990$

Bleeker FE, Lamba S, Rodolfo M, Scarpa A, Leenstra S, Vandertop WP, Bardelli A (2009) Mutational profiling of cancer candidate genes in glioblastoma, melanoma and pancreatic carcinoma reveals a snapshot of their genomic landscapes. Hum Mutat 30: E451-E459

Boland CR, Thibodeau SN, Hamilton SR, Sidransky D, Eshleman JR, Burt RW, Meltzer SJ, Rodriguez-Bigas MA, Fodde R, Ranzani GN, Srivastava S (1998) A National Cancer Institute Workshop on Microsatellite Instability for cancer detection and familial predisposition: development of international criteria for the determination of microsatellite instability in colorectal cancer. Cancer Res 58: $5248-5257$

Brand S (2009) Crohn's disease: Th1, Th17 or both? The change of a paradigm: new immunological and genetic insights implicate Th17 cells in the pathogenesis of Crohn's disease. Gut 58: 1152-1167

Caldwell CM, Green RA, Kaplan KB (2007) APC mutations lead to cytokinetic failures in vitro and tetraploid genotypes in Min mice. J Cell Biol 178: $1109-1120$

Chung DC (2000) The genetic basis of colorectal cancer: insights into critical pathways of tumorigenesis. Gastroenterology 119: 854-865

Cleton-Jansen AM, Callen DF, Seshadri R, Goldup S, Mccallum B, Crawford J, Powell JA, Settasatian C, van Beerendonk H, Moerland EW, Smit VT, Harris WH, Millis R, Morgan NV, Barnes D, Mathew CG, Cornelisse CJ (2001) Loss of heterozygosity mapping at chromosome arm 16q in 712 breast tumors reveals factors that influence delineation of candidate regions. Cancer Res 61: 1171-1177
In conclusion, NAV3 copy number changes may provide at least two growth advantages to a subpopulation of tumour cells. Tumour cells with NAV3 aberrations and abnormal localisation of beta-catenin would become less susceptible to growth control mechanisms by surrounding cells, whereas they also become more susceptible to growth promotion by tissue inflammatory signals, including IL23. Our demonstration that NAV3 aberrations are linked to inflammation and cell proliferation pathways, and finally to lymph node metastasis, may thus identify the cell population responsible for the spread of the initially local tumour.

\section{ACKNOWLEDGEMENTS}

This work was supported by grants from the Finnish Cancer Research Foundation (AR, PP), Academy of Finland (PP, WA-R, $\mathrm{SH})$, Sigrid Jusélius Foundation (PP, SH, AR), Helsinki University Hospital Research Funds (AR), Tampere University Hospital Research Funds (KK), Finska Läkaresällskapet (EC, AR), Finnish Funding Agency for Technology and Innovation (KK, AR), The Finnish Medical Foundation (LK), Maud Kuistila Memorial Foundation (LK) and Helsinki Biomedical Graduate School (KO). We thank Mrs Marianne Karlsberg (CliniXion Ltd, Tampere, Finland) and Sanna Virtanen, MSc (Dermagene Oy) for performing the FISH assays, Mrs Jonna Varis for cell culturing, Mrs Kaija Järvinen for performing the immunohistochemistry assays, and Mrs Marjukka Nykänen for constructing the tissue microarrays.

Supplementary Information accompanies the paper on British Journal of Cancer website (http://www.nature.com/bjc)

Debauve G, Capouillez A, Belayew A, Saussez S (2008) The helicase-like transcription factor and its implication in cancer progression. Cell Mol Life Sci 65: $591-604$

DeNardo DG, Johansson M, Coussens LM (2008) Inflaming gastrointestinal oncogenic programming. Cancer Cell 14: 7-9

Einarsdottir E, Koskinen LL, Dukes E, Kainu K, Suomela S, Lappalainen M, Ziberna F, Korponay-Szabo IR, Kurppa K, Kaukinen K, Adany R, Pocsai Z, Szeles G, Farkkila M, Turunen U, Halme L, Paavola-Sakki P, Not T, Vatta S, Ventura A, Lofberg R, Torkvist L, Bresso F, Halfvarson J, Maki M, Kontula K, Saarialho-Kere U, Kere J, D'Amato M, Saavalainen P (2009) IL23R in the Swedish, Finnish, Hungarian and Italian populations: association with IBD and psoriasis, and linkage to celiac disease. $B M C$ Med Genet 10: 8

Endo-Munoz L, Dahler A, Teakle N, Rickwood D, Hazar-Rethinam M, Abdul-Jabbar I, Sommerville S, Dickinson I, Kaur P, Paquet-Fifield S, Saunders N (2009) E2F7 can regulate proliferation, differentiation, and apoptotic responses in human keratinocytes: implications for cutaneous squamous cell carcinoma formation. Cancer Res 69: 1800-1808

Fearon ER, Vogelstein B (1990) A genetic model for colorectal tumorigenesis. Cell 61: 759-767

Gardner S, Pawson AJ (2009) Emerging targets of the GnRH receptor: novel interactions with Wnt signalling mediators. Neuroendocrinology 89: $241-251$

Gertz EM, Sengupta K, Difilippantonio MJ, Ried T, Schaffer AA (2009) Evaluating annotations of an Agilent expression chip suggests that many features cannot be interpreted. BMC Genomics 10: 566

Gordon MD, Nusse R (2006) Wnt signaling: multiple pathways, multiple receptors, and multiple transcription factors. J Biol Chem 281: $22429-22433$

Hahtola S, Burghart E, Jeskanen L, Karenko L, Abdel-Rahman WM, Polzer B, Kajanti M, Peltomaki P, Pettersson T, Klein CA, Ranki A (2008a) Clinicopathological characterization and genomic aberrations in subcutaneous panniculitis-like T-cell lymphoma. J Invest Dermatol 128: $2304-2309$ 
Hahtola S, Burghart E, Puputti M, Karenko L, Abdel-Rahman WM, Vakeva L, Jeskanen L, Virolainen S, Karvonen J, Salmenkivi K, Kinnula V, Joensuu H, Peltomaki P, Klein CA, Ranki A (2008b) Cutaneous T-cell lymphoma-associated lung cancers show chromosomal aberrations differing from primary lung cancer. Genes Chromosomes Cancer 47: $107-117$

Holtta V, Klemetti P, Sipponen T, Westerholm-Ormio M, Kociubinski G, Salo H, Rasanen L, Kolho KL, Farkkila M, Savilahti E, Vaarala O (2008) IL-23/IL-17 immunity as a hallmark of Crohn's disease. Inflamm Bowel Dis 14: $1175-1184$

Houlston RS, Cheadle J, Dobbins SE, Tenesa A, Jones AM, Howarth K, Spain SL, Broderick P, Domingo E, Farrington S, Prendergast JG, Pittman AM, Theodoratou E, Smith CG, Olver B, Walther A, Barnetson RA, Churchman M, Jaeger EE, Penegar S, Barclay E, Martin L, Gorman M, Mager R, Johnstone E, Midgley R, Niittymaki I, Tuupanen S, Colley J, Idziaszczyk S, Thomas HJ, Lucassen AM, Evans DG, Maher ER, Maughan T, Dimas A, Dermitzakis E, Cazier JB, Aaltonen LA, Pharoah P, Kerr DJ, Carvajal-Carmona LG, Campbell H, Dunlop MG, Tomlinson IP, COGENT Consortium, CORGI Consortium, COIN Collaborative Group, COINB Collaborative Group (2010) Meta-analysis of three genome-wide association studies identifies susceptibility loci for colorectal cancer at 1q41, 3q26.2, 12q13.13 and 20q13.33. Nat Genet 42: 973-977

Hyytinen E, Visakorpi T, Kallioniemi A, Kallioniemi OP, Isola JJ (1994) Improved technique for analysis of formalin-fixed, paraffin-embedded tumors by fluorescence in situ hybridization. Cytometry 16: 93-99

Isola J, DeVries S, Chu L, Ghazvini S, Waldman F (1994) Analysis of changes in DNA sequence copy number by comparative genomic hybridization in archival paraffin-embedded tumor samples. Am J Pathol 145: $1301-1308$

Joensuu EI, Abdel-Rahman WM, Ollikainen M, Ruosaari S, Knuutila S, Peltomaki P (2008) Epigenetic signatures of familial cancer are characteristic of tumor type and family category. Cancer Res 68: $4597-4605$

Kalari S, Pfeifer GP (2010) Identification of driver and passenger DNA methylation in cancer by epigenomic analysis. Adv Genet 70: 277-308

Karenko L, Hahtola S, Paivinen S, Karhu R, Syrja S, Kahkonen M, Nedoszytko B, Kytola S, Zhou Y, Blazevic V, Pesonen M, Nevala $\mathrm{H}$, Nupponen N, Sihto H, Krebs I, Poustka A, Roszkiewicz J, Saksela K, Peterson P, Visakorpi T, Ranki A (2005) Primary cutaneous T-cell lymphomas show a deletion or translocation affecting NAV3, the human UNC-53 homologue. Cancer Res 65: 8101-8110

Kim BG, Li C, Qiao W, Mamura M, Kasprzak B, Anver M, Wolfraim L, Hong S, Mushinski E, Potter M, Kim SJ, Fu XY, Deng C, Letterio JJ (2006) Smad4 signalling in T cells is required for suppression of gastrointestinal cancer. Nature 441: 1015-1019

Kinzler KW, Vogelstein B (1996) Lessons from hereditary colorectal cancer. Cell 87: $159-170$

Kugathasan S, Saubermann LJ, Smith L, Kou D, Itoh J, Binion DG, Levine AD, Blumberg RS, Fiocchi C (2007) Mucosal T-cell immunoregulation varies in early and late inflammatory bowel disease. Gut 56: $1696-1705$

Lakatos PL, Szamosi T, Szilvasi A, Molnar E, Lakatos L, Kovacs A, Molnar T, Altorjay I, Papp M, Tulassay Z, Miheller P, Papp J, Tordai A, Andrikovics H, Hungarian IBD Study Group (2008) ATG16L1 and IL23 receptor (IL23R) genes are associated with disease susceptibility in Hungarian CD patients. Dig Liver Dis 40: 867-873

Leary RJ, Lin JC, Cummins J, Boca S, Wood LD, Parsons DW, Jones S, Sjoblom T, Park BH, Parsons R, Willis J, Dawson D, Willson JK, Nikolskaya T, Nikolsky Y, Kopelovich L, Papadopoulos N, Pennacchio LA, Wang TL, Markowitz SD, Parmigiani G, Kinzler KW, Vogelstein B, Velculescu VE (2008) Integrated analysis of homozygous deletions, focal amplifications, and sequence alterations in breast and colorectal cancers. Proc Natl Acad Sci USA 105: 16224-16229
MacDonald BT, Tamai K, He X (2009) Wnt/beta-catenin signaling: components, mechanisms, and diseases. Dev Cell 17: 9-26

Maliniemi P, Carlsson E, Kaukola A, Ovaska K, Niiranen K, Saksela O, Jeskanen L, Hautaniemi S, Ranki A (2011) NAV3 copy number changes and target genes in basal and squamous cell cancers. Exp Dermatol 20: 926-931

Nord H, Hartmann C, Andersson R, Menzel U, Pfeifer S, Piotrowski A, Bogdan A, Kloc W, Sandgren J, Olofsson T, Hesselager G, Blomquist E, Komorowski J, von Deimling A, Bruder CE, Dumanski JP, Diaz de Stahl $\mathrm{T}$ (2009) Characterization of novel and complex genomic aberrations in glioblastoma using a 32K BAC array. Neuro Oncol 11: 803-818

Ovaska K, Laakso M, Haapa-Paananen S, Louhimo R, Chen P, Aittomaki V, Valo E, Nunez-Fontarnau J, Rantanen V, Karinen S, Nousiainen K, Lahesmaa-Korpinen AM, Miettinen M, Saarinen L, Kohonen P, Wu J, Westermarck J, Hautaniemi S (2010) Large-scale data integration framework provides a comprehensive view on glioblastoma multiforme. Genome Med 2: 65

Phelps RA, Chidester S, Dehghanizadeh S, Phelps J, Sandoval IT, Rai K, Broadbent T, Sarkar S, Burt RW, Jones DA (2009) A two-step model for colon adenoma initiation and progression caused by APC loss. Cell 137: $623-634$

Polakis P (1997) The adenomatous polyposis coli (APC) tumor suppressor. Biochim Biophys Acta 1332: F127 - F147

Ranki A, Vakeva L, Sipila L, Krohn K (2011) Molecular markers associated with clinical response to bexarotene therapy in cutaneous T-cell lymphoma. Acta Derm Venereol 91: 568-573

Reuter JA, Ortiz-Urda S, Kretz M, Garcia J, Scholl FA, Pasmooij AM, Cassarino D, Chang HY, Khavari PA (2009) Modeling inducible human tissue neoplasia identifies an extracellular matrix interaction network involved in cancer progression. Cancer Cell 15: 477-488

Salisbury TB, Binder AK, Nilson JH (2008) Welcoming beta-catenin to the gonadotropin-releasing hormone transcriptional network in gonadotropes. Mol Endocrinol 22: 1295-1303

Silverberg MS, Cho JH, Rioux JD, McGovern DP, Wu J, Annese V, Achkar JP, Goyette P, Scott R, Xu W, Barmada MM, Klei L, Daly MJ, Abraham C, Bayless TM, Bossa F, Griffiths AM, Ippoliti AF, Lahaie RG, Latiano A, Pare P, Proctor DD, Regueiro MD, Steinhart AH, Targan SR, Schumm LP, Kistner EO, Lee AT, Gregersen PK, Rotter JI, Brant SR, Taylor KD, Roeder K, Duerr RH (2009) Corrigendum: ulcerative colitis-risk loci on chromosomes $1 \mathrm{p} 36$ and 12q15 found by genome-wide association study. Nat Genet 41: 762

Soon P, Gill A, Benn D, Clarkson A, Robinson B, McDonald K, Sidhu S (2009) Microarray gene expression and immunohistochemistry analyses of adrenocortical tumours identify IGF2 and Ki-67 as useful in differentiating carcinomas from adenomas. Endocr Relat Cancer 16: $573-583$

Vogelstein B, Fearon ER, Hamilton SR, Kern SE, Preisinger AC, Leppert M, Nakamura Y, White R, Smits AM, Bos JL (1988) Genetic alterations during colorectal-tumor development. $N$ Engl J Med 319: 525-532

Wood LD, Parsons DW, Jones S, Lin J, Sjoblom T, Leary RJ, Shen D, Boca SM, Barber T, Ptak J, Silliman N, Szabo S, Dezso Z, Ustyanksky V, Nikolskaya T, Nikolsky Y, Karchin R, Wilson PA, Kaminker JS, Zhang Z, Croshaw R, Willis J, Dawson D, Shipitsin M, Willson JK, Sukumar S, Polyak K, Park BH, Pethiyagoda CL, Pant PV, Ballinger DG, Sparks AB, Hartigan J, Smith DR, Suh E, Papadopoulos N, Buckhaults P, Markowitz SD, Parmigiani G, Kinzler KW, Velculescu VE, Vogelstein B (2007) The genomic landscapes of human breast and colorectal cancers. Science 318: $1108-1113$

Xie J, Itzkowitz SH (2008) Cancer in inflammatory bowel disease. World J Gastroenterol 14: 378 - 389

Yang SK, Park M, Lim J, Park SH, Ye BD, Lee I, Song K (2009) Contribution of IL23R but not ATG16L1 to Crohn's disease susceptibility in Koreans. Inflamm Bowel Dis 15: 1385-1390

This work is published under the standard license to publish agreement. After 12 months the work will become freely available and the license terms will switch to a Creative Commons Attribution-NonCommercial-Share Alike 3.0 Unported License. 